\title{
Competency by design: when opportunity stops knocking
}

\author{
Jason Waechter, MD
}

Received: 17 June 2016/Revised: 10 October 2016/Accepted: 3 November 2016/Published online: 23 November 2016

(c) Canadian Anesthesiologists' Society 2016

The Royal College of Physicians and Surgeons of Canada (RCPSC) is transitioning residency training to a program of competency by design (CBD). This program differs from our current training model, to which I refer as competency by opportunity (CBO) as this traditional model typically relies on clinical opportunities for obtaining competence.

An important focus of the Competency Based Medical Education (CBME) transition is the assessment of trainees for new CBD standards. For example, Chiu et al. concluded in their article on simulation that the CBME "initiative requires major changes to all residency education programs, including an increased quantity and diversity in assessment modalities." ${ }^{1}$ Although clearly an essential requirement, the actual assessment comes after the teaching. The purpose of this letter is to highlight what I believe could be a component of CBD that is not receiving enough attention. The recent, well-written article in the Journal by Levine and Shorten appropriately draws attention to skills acquisition, deliberate practice, and feedback during the CBD transition. ${ }^{2}$

Consider the following mathematical analysis of CBO. Using intubation as an example, we could predict how many times anesthesia residents might intubate patients during their training. Assuming approximately two intubations per day, five days a week, with four weeks per rotation, and 30 anesthesia rotations during the fiveyear training program, 1,200 (i.e., $2 \times 5 \times 4 \times 30$ ) intubations per resident are predicted. If it were true that for $99 \%$ of all anesthesia residents the learning curve for acquiring intubation competence required $<1,200$

J. Waechter, MD $(\bowtie)$

Departments of Critical Care and Anesthesiology,

University of Calgary, Calgary, AB, Canada

e-mail: jwaech@yahoo.ca intubations, the CBO model would provide enough practice and feedback for $99 \%$ of our residents. Thus, the CBO model works for intubation training, although it may not be usable for all areas of competence.

We must compare two variables to define the challenge. The first variable is how many of instances of practice and feedback are required to attain a given skill - which is likely different for each trainee. The second variable is how many instances of practice and feedback each trainee actually experiences during his or her training. Research that addresses learning curves is required to provide the first variable. Logbooks could be used to obtain the data needed to address the second variable. Without both data points, it is difficult to know the probability that a training program will meet the practice and feedback requirements of its trainees.

Our existing CBO model erroneously assumes that the trainee will encounter all of the scenarios he or she requires, will encounter each scenario enough times to obtain competence, and will receive sufficient feedback for each scenario encountered. For less commonly encountered scenarios, it is highly probable that the CBO model will not provide enough practice or feedback for trainees, resulting in trainees having a high probability of graduating without competence in those specific areas. Thus, this scenario defines the importance of the need to convert to the CBD model.

Simulation is one method for providing practice and feedback for less commonly encountered skills. A training program could guarantee that $100 \%$ of their trainees would be exposed to intraoperative hyperthermia (or other rare scenario) a minimum number of times. The performance of the trainee could be assessed according to milestones and entrustable professional activities. The simulation can be 
repeated as many times as is required for each trainee to demonstrate competence.

A second example is electrocardiogram (ECG) interpretation. There are easily $>30$ ECG diagnoses for which an anesthesiologist must demonstrate competence (ignoring combinations of diagnoses). The learning curve for these diagnoses is not known, but if we assumed that each diagnose is needed to be practiced five times to achieve competence along with long-term retention, then each trainee would require 150 (i.e., $30 \times 5$ ) practice opportunities and, importantly, feedback. If there were 20 residents in a training program, and the institution subscribes to the belief that it is the responsibility of the training program to provide the trainees with both practice and feedback, the program would need to provide 3,000 (i.e., $150 \times 20$ ) instances of structured practice and 3,000 instances of feedback! Furthermore, 150 ECGs presented to the trainees are not those randomly encountered in a clinical environment (where at least $50 \%$ could be entirely normal); these ECGs have been selected by design for their diagnoses, a concept known as deliberate practice. $^{3}$ Now consider scaling this challenge of providing deliberate practice to include interpretation skills with chest radiographs, arterial blood gas evaluations, and pulmonary function tests (among others). The CBD mathematics thus becomes overwhelming. This challenge represents an opportunity for innovation in medical education.

Competence assessment is, of course, a critical component of training, but in preparing our trainees for assessment and transitioning to $\mathrm{CBD}$, we must be aware of learners' needs so we can fill the existing opportunistic learning gaps with future designed learning solutions.

Competing interest Jason Waechter is the founder of teachingmedicine.com, a medical education website.

Editorial responsibility This submission was handled by Dr. Hilary P. Grocott, Editor-in-Chief, Canadian Journal of Anesthesia.

\section{References}

1. Chiu M, Tarshis J, Antoniou A, et al. Simulation-based assessment of anesthesiology residents' competence: development and implementation of the Canadian National Anesthesiology Simulation Curriculum (CanNASC). Can J Anesth 2016. DOI:10. 1007/s12630-016-0733-8.

2. Levine MF, Shorten G. Competency-based medical education: Its time has arrived. Can J Anesth 2016. DOI:10.1007/s12630-0160638-6.

3. Pusic M, Pecaric M, Boutis K. How much practice is enough? Using learning curves to assess the deliberate practice of radiograph interpretation. Acad Med 2011; 86: 731-6. 